\title{
ACRL in Chicago ACRL programs at the ALA Annual Conference
}

A LA's 124th Annual Conference was held June 23-29, 2005, in Chicago. Approximately 27,800 librarians, library support staff, exhibitors, writers, educators, publishers, and special guests attended the conference, surpassing last year's attendance by more than 8,000. Ed. note: Thanks to the ACRL members who summarized programs to make this report possible. "generational caverns" and connect with students by understanding what students have always known (computers have always fit in their backpacks) or will never know (the "return" key).

Silver, founder of the Resource Center for Cyberculture Studies and codirector of The September Project, described how technologies-DVD, TiVo, MP3, cell phone-help to shape students' cultural realities, as well as

“ACRL rocks!” Frances Maloy set an enthusiastic tone for her President's Program, "Time for a reality check: Academic libraries in a TiVo-lutionary Age," when she proclaimed that "ACRL rocks!" Her words resonated as Tom McBride and Ron Nief (both of Beloit College) and David Silver (University

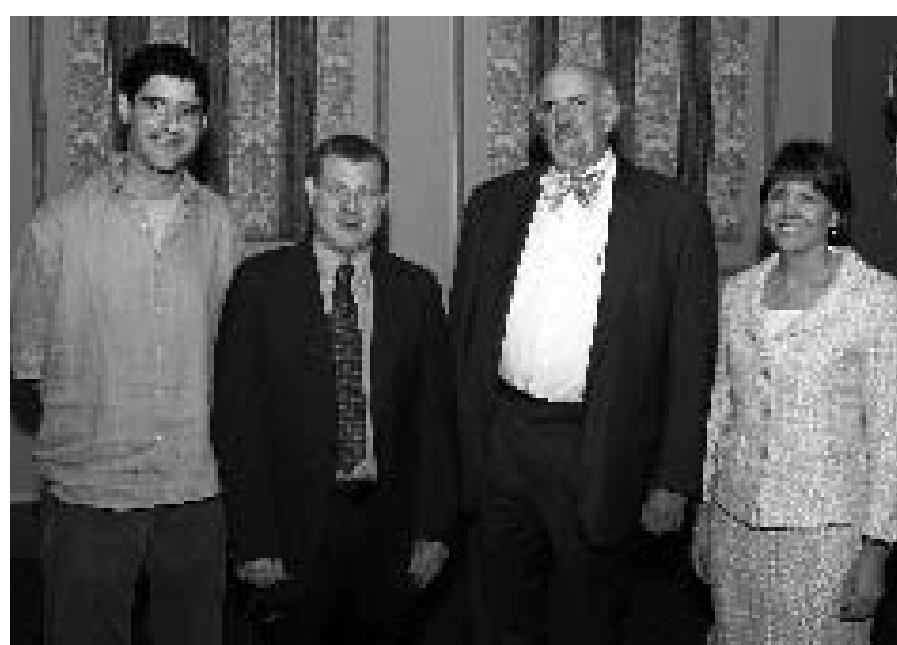

The 2005 President's Program speakers (left to right): David M. Silver, assistant professor in the Department of Communication at the University of Washington; Tom McBride, professor of English and Keefer Professor of the Humanities at Beloit College; Ron Nief, public affairs director at Beloit College; and 2004-05 ACRL President Frances Maloy. of Washington) immersed the audience in the mindsets of the 18-to-22-year-old students that we serve each day.

Representing the Beloit College Mindset List, McBride and Nief used humorous examples to show that teaching faculty and librarians must be aware that incoming students have been influenced by societal trends different from our own. We can bridge foster their creativity and curiosity. Students expect the appealing characteristics of these technologiescheap, fast, easily accessible, and easily distributed-to be givens in their lives. Libraries can use these "givens" to pull students in by offering free and comfortable public spaces where they can drink caffeine, chat with friends, use wireless technology, and be challenged to think critically.

In the end, Silver reminds us that despite iPods and cell phones, our students remain essentially the same-they are reading and writing- -just on a screen and with more typos."-Jessica Albano, University of Washington,jalbano@u.washington.edu 


\section{Distance learning}

The Distance Learning Section program, "Distance learning: We know where we've been, but where are we going?" featured three speakers who covered distinct topics. Arthur Young's (Northern Illinois University) presentation, "Leadership attributes, mature learners, and distance education," described traits that library directors need, and divided them into these categories:

1) managerial: commitment to service, results orientation, ability to communicate effectively, ability to develop a shared vision

2) personal: credibility, evenhandedness, commitment to values, ability to handle stress

3) knowledge or skills: library operations, scholarly communication, digital libraries, planning

Young discussed other leadership studies and mentioned the need for more research on leadership attributes. The graying of the distance learners themselves is an important trend with its implications for library services.

Ashley Bonnette (University of Louisiana-Lafayette) asked the question, "How do diversity issues affect distance learning?" She explained that diversity among the learners in distance education and the rising numbers of Latinos and African Americans in the population at-large will affect the makeup of classes. There is a possibility of miscommunication among students because of cultural differences, possibly aggravated by the lack of face-to-face contact.

Karen Brown's (Graduate School of Library and Information Science at Dominican University) presentation, "Providing distance learning library services: Are new MLS graduates ready?" encouraged practitioners to welcome new graduates for their enthusiasm and strong service orientation. She hopes for more training about working with distance learners and more focus on the teachinglearning process, especially learning styles and adult education theory.-Margaret Casado, University of Tennessee-Knoxville, casado@utk.edu

\section{Bits and bytes}

During the College Libraries Section conference program, "Bits and bytes: Using technology to train academic librarians as coaches," four speakers shared their experiences with two different online coaching programs designed for librarians. Melanie Hawks (ARL) and Juli Hinz (University of Utah) spoke about "Coaching for performance" from a program designer and a participant perspective. Program goals included self-directed learning, engagement of different learning styles, creation of a geographically dispersed community, and more personalized interactions between facilitators and participants than are possible in an in-person, time-limited setting with 35 students.

Challenges included using communitybuilding tools, such as chat, in which the technology itself and time differences were barriers. Unstructured discussion forums were not a success, as participants needed specific assignments and reminders to generate online activity. Successes included access to rich content and expertise in a setting customizable to a participant's local situation.

Kathryn Deiss (Metropolitan Library System) and Sonia Bodi (North Park University) spoke about the Teach*Model*Coach program, developed with Institute of Museum and Library Services funding for Chicago's Metropolitan Library System. The program used a combination of in-person and online tools and meetings for both the whole group and active learning sessions between individual learners and coaches.

One difficulty was that many school librarians were not able to effectively participate in chat sessions, where much serendipitous learning occurred, due to low-speed Internet access and/or instant messaging restrictions. Overall learning through immersion in the topic supplemented by technological tools was very successful.

Both programs enjoyed technological successes and challenges, and attendees of this session learned a lot.-Megan Fitch, Kenyon College,tchm@kenyon.edu 


\section{Getting published}

Theresa Kemp, coeditor of Feminist Teacher, and Karyle Butcher, editorial board member for portal: Libraries and the Academy, gave advice on getting published at this year's Women's Studies Section (WSS) program, "Getting published: From practice to print."

Kemp (University of Wisconsin-EauClaire) emphasized that Feminist Teacher has never accepted anything without suggested revisions, and she encouraged writers to take advantage of this mentoring. She urged librarians to consider Feminist Teacher as a publication outlet, particularly for reviews and pieces about integrating feminist pedagogy into library instruction.

Butcher (Oregon State University) argued for publication as a means to share ideas, keep a historical record of accomplishment, and provide much-needed recognition, then she outlined the major obstacles to publishing as follows: the fact that publishing is not a choice for tenure-track librarians, the terminal master's degree means librarians may not have a research background, institutional culture may not foster research, and no one ever has enough time. She insisted that librarians must learn to value themselves enough to carve time out from helping other people do their own research.

As advice for new librarians, Butcher recommended choosing topics by looking at issues in their libraries and suggested book reviews, poster sessions, and coauthoring as ways of getting started.

From her editorial perspective, Butcher offered insight as to why articles get turned down: they didn't answer the "so what" question, poor statistical analysis, bad writing, submission to inappropriate journals, and bad luck. But take heart, as Ruth Dickstein, WSS chair, urged: "Rejection happens to all of us."-Jennifer Gilley, Pennsylvania State-New Kensington Library, jrg15@psu.edu

\section{Humanize the machine}

Kristine Anderson (Purdue University) moderated the Literatures in English Section program (cosponsored by Rare Books and
Manuscripts Section), "Old texts made new: EEBO, ECCO, and the impact on literary scholarship," which brought together librarians and scholars to discuss how full text influences the nature of research. The panelists were Jesse Lander (University of Notre Dame), Helen Thompson, and Jeffrey Garrett (both of Northwestern University).

New technology, Lander remarked, always entails gains and losses. Keyword searching, for example, is both heralded as a check against information overload and decried as a shortcut that diminishes learning. Digital collections do facilitate particular research projects, such as attribution studies and cultural history. Keyword searches, Lander observed, are like boreholes: "You need to do a lot of them to demonstrate anything."

Thompson reported that after using Gale's Eighteenth Century Collections Online (ECCO) she is "unable to determine whether she has killed two birds, one bird, or no birds." Access to full-text, however, can lead to "new disciplinary self-scrutiny," and a redefinition of the literary canon. This illumination does not happen when she downloads, she observed, but rather when she reads the texts.

Drawing extensively from the works of librarian Jorge Luis Borges, Garrett wondered what the human mind brings to the process of memory that machines do not. Metaphorical language, he noted, is particularly difficult for search engines to cope with, and, yet, is key to the way people grapple with reality. Even as technology advances, "librarians humanize the machine to make it serve us on our own terms."-Steven R. Harris, Utah State University, Steven.Harris@usu.edu

\section{Science librarians in the 21 st century}

The Science and Technology Section program, "The new crossroads: Science librarians in the 21st century," explored the future role of science and technology librarians.

Mary Case (University of Illinois-Chicago) provided an overview of issues and trends in scholarly communication, including rising journal prices, commercial publishers, open 


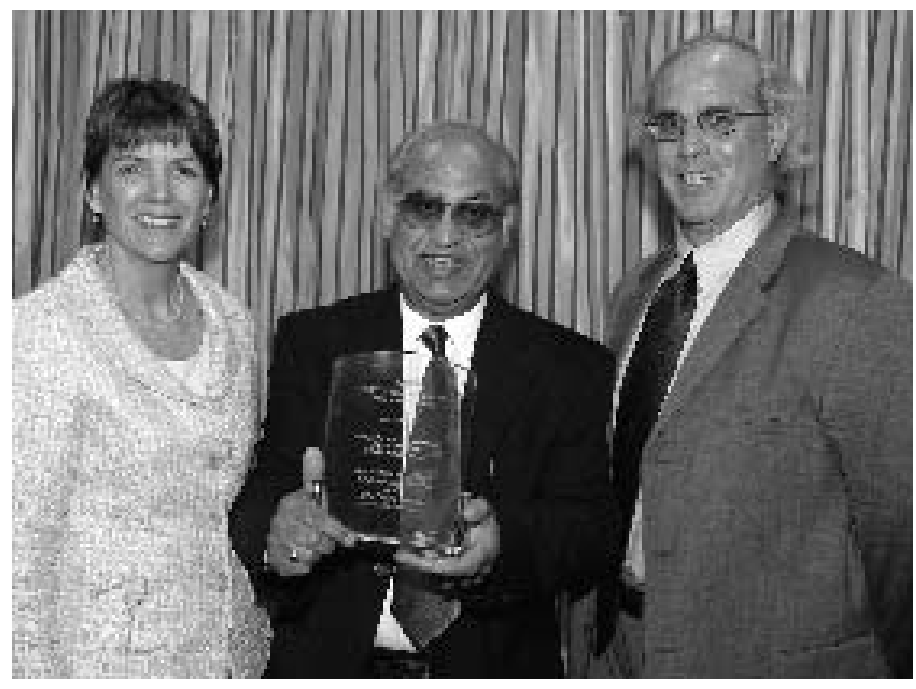

ACRL's 2005 Academic/Research Librarian of the Year R. N. Sharma, director of the University Library at West Virginia State University (center), with 2004-05 ACRL President Frances Maloy and Bob Nardini, senior vice president of YBP Library Services.

and public access, and digital repositories and discussed their impact on the future role of science librarians.

Mel DeSart (University of Washington-Seattle) presented tips for helping users, such as going to them and bringing them into the library using various methods, proving the relevance of science librarians by collecting statistics and testimonials and creating a niche, and attracting qualified people to the profession by offering scientific courses in library schools more frequently and having science librarians teach these courses and recruit students.

Alison Ricker (Oberlin College) described popular and emerging technologies used by NetGens, including instant messaging, wikis, RSS feeds, weblogs, podcasting, and cellular phones. Examples of how these technologies are used and methods for incorporating them into libraries were provided.

Michael Leach (Harvard University) discussed the future role of science librarians as research, digital objects, and education librarians. Participating in research through user needs analysis, scholarly communication, and collaborative opportunities; developing and aggregating digital objects; and educating users by promoting science information literacy, learning about interdisciplinary research, and developing teaching skills are of importance.

The presentations are available on the STS Web site under conference programs (www.acrl. org/sts)._Jennifer Long, University of Alabama at Birmingham, jmlong@uab.edu

\section{Pay to play}

Cosponsored with ACRL's Scholarly Communications Committee, the University Libraries Section presented, "Pay to play: Debating models of scholarly publishing." The program featured two speakers discussing emerging models of publishing and disseminating scholarship and the role of university libraries in supporting and sustaining access to scholarly materials.

Marianne Gaunt (Rutgers University) began by defining open access and describing various distribution and business models. She then detailed the reactions of faculty, scholarly societies, commercial publishers, government agencies, and libraries to these models. Faculty can be resistant to placing materials in repositories due to concerns about author fees and the prestige of open access journals. Scholarly societies, commercial publishers, and government agencies often have conflicting concerns, such as a desire to protect revenues, the need to maintain a balance in publications by the scientific and nonscientific disciplines, the assurance of the quality of pay for publication articles, and open access to research. Libraries can help democratize access, but for now there are no blanket solutions. Experimentation with various models is necessary at this point.

Following Gaunt's presentation, Daniel Greenstein (California Digital Library) described the e-scholarship repository at the University of California. This collection includes peer-reviewed, born-digital works that have a potential for publication. While Greenstein predicts that special collections departments of the future will focus on what needs 
to be preserved digitally, he also suggested pushing the level of authority for "communities" within repositories to authors and departments._Leslie Madden, Georgia Institute of Technology, leslie.madden@library.gatech. edu, leslie.madden@library.gatech.edu

\section{Are subject librarians an endangered species?}

One hundred eighteen attendees heard a moderated panel of subject specialists answer the question posed by the program, "Are subject librarians an endangered species?" The program was sponsored by the Anthropology and Sociology Section (ANSS) and featured Daniel Tsang (University of California-Irvine), Darlene Nichols (University of Michigan-Ann Arbor), Jane McKeever (University of Chicago), and Kara Whatley (New York University). Wade Kotter (Weber State University and ANSS chair) moderated using a prepared list of questions.

The ANSS program clarified how subject librarians in a rapidly changing work environment continue to perform critical tasks to build collections. As the program progressed, the level of intensity in questions struck issues like the impact of Google, information explosion and keyword searching, alternative publishing, interdisciplinary research, scholarly communication, serials vs. monographs budgets, subject specialization, Ph.D. education, and the second master's in collection development.

The audience asked questions about information literacy challenges and new subject librarian training. It was said that libraries need subject specialists to build diverse collections that reflect the specific interests of their colleges. Library budgets must be maintained accordingly. Overall, subject selectors are empowered by new technology to excel in their work.

Attendees evaluated the program highly; it was timely and relevant to their professional goals. The informal and interactive format was appreciated, as was the diversity of the panelists. Some drawbacks concerned the length of the program.
Resources related to the program can be found on the ANSS Web site located at www.Lib.odu.edu/ANSS._Pauline D. Manaka, University of California-Irvine, pdmanaka@lib.uci.edu; Mimmo Bonanni, Arizona State University,mimmo@asu.edu

\section{Tenure and continuous employment}

Carolyn Allen, incoming chair of the ACRL Committee on the Status of Academic Librarians, introduced the committee's program: "Tenure and continuous employment: Is it worth it?"

Margaret Mering (University of NebraskaLincoln [UNL]) presented the viewpoint of a librarian who has gone through the process of achieving tenure and promotion to full professor. She described UNL's scholar-practitioner model for faculty positions, including adjustments to leave and travel policies for nontenured faculty. Mering also addressed the question of granting tenure at the time of hire for faculty who have earned tenure at a different institution.

Dale Canelas (University of Florida [UF]) spoke from the perspective of a library director. At UF, requirements are similar to those for classroom faculty in many ways, but those relating to publication are less stringent. Institutional support at UF includes an allocation of 10 percent of librarian's time devoted to research and a mentoring program. The tenure process provides documented evidence that a librarian has become involved with the national profession, which improves visibility for the institution and the individual.

Bob Smith (University of Arkansas) presented the observations of a provost in a more theoretical context. With specific librarians as examples, he explained his concept of developing integrated faculty. In an allusion to the Greek myth of Theseus and the Minotaur, Smith likened librarians to Ariadne's golden thread, leading people through a maze of information.

The implied answer to the title question was a qualified "yes." All of the panelists emphasized that the tenure process requires adequate administrative support, and, even 
with support, not all librarians fare well in this environment.-Sharon McCaslin, Fontbonne University, smccaslin@fontbonne.edu

\section{Collecting world cultures}

The Rare Books and Manuscripts Section (RBMS) sponsored the program "Collecting world cultures: African, Asian, Caribbean, and Native American materials in Chicago institutions." Speakers from Northwestern University, the University of Illinois-Chicago (UIC), the Newberry Library, and the University of Chicago (UC) discussed the issues, challenges, and responsibilities involved in collecting and managing treasured cultural materials.

David Easterbrook (Melville J. Herskovits Library of African Studies at Northwestern University) described the library's efforts to make the collection available to everyone, regardless of affiliation. As the largest separate collection of African studies research material in existence, the Herskovits Library serves a range of readers, from African refugees in Chicago to national politicians. In recent years, the library has made efforts to share its unique collections with a wider audience, with the help of digital technology.

UIC has also made use of digital tools to share cultural materials with a worldwide audience. After purchasing the H. D. Carberry Collection of Caribbean Studies in 1997, UIC decided to scan approximately 600 book jacket covers from the collection and make them available on the Internet. According to Nancy John (UIC), this project was a way to "give something back to the region." Nancy Cirillo (UIC) noted that the book jackets are a "pictorial representation of the first major wave of Caribbean writers in England," and thus pertain to a broad range of academic pursuits.

Brian Hosmer, (D'Arcy McNickle Center for American Indian Studies at the Newberry Library) discussed the importance of being good stewards of cultural material. According to Hosmer, "building bridges [with native peoples] ranks amongst our most important priorities." The Newberry's Lannan Summer
Institutes for teachers in tribal colleges represents one such bridge. By extending outward and drawing people through the doors, the Newberry is "little by little forging quite constructive relations with tribal communities."

James Nye, (South Asia Language and Area Center at UC) relayed his institution's efforts to preserve collections in South Asia. Since 1992, UC has been engaged in a "catch and release" strategy. UC arranges the purchase of large, rare collections, develops and implements preservation and cataloging strategies, and later cedes the collections to South Asian institutions. Preservation copies are sent to the United States for scholarly use. As Nye explains, "there is greater joy and strength in working in numbers." A few benefits of the "catch and release" method include improved access to hard-to-find materials, the preservation of rare and fragile materials, and even the start of a new library movement in South Asia.-Katie McMabon, Newberry Library, mcmahonk@newberry.org

\section{Educational research}

The Educational and Behavioral Sciences Section presented "Empirical desires, realized dreams: Quantitative and qualitative research in the era of "No Child Left Behind." The panel included Lisa Markman (Princeton University), Harrison Dekker (University of California-Berkeley), and Craig B. Howley and Aimee Howley (both from Ohio University). Each panelist brought a unique perspective on the development, use, and abuse of educational research and praxis-whether desired or dreamed of.

Markman discussed scientifically based research, which involves externally peer-reviewed, systematic, and empirical methods of experimentation using hypothesis testing and employing a clear and detailed elaboration of methods and results. Researchers and educators should work together to provide ethical educational experimentation that includes quantitative measurements and rich, qualitative description.

Dekker commented on the role of librarians as contributors to educational praxis as 
legislation helps to popularize the use of data. An example from the Mellon Library Faculty Fellowship for Undergraduate Research is a course on experiencing education and diversity.

Aimee and Craig Howley used the metaphor of poultry farming to explain that educational research is flawed and incomplete; it wrongly assumes that educational practices work uniformly across populations, is replicable, and conflates experimental and real-life conditions. Education research must take into account real-life experiences and communities; it must be ethical and focus on creating a democratic and thoughtful population engaged in questioning the aims of education, not searching for what works.-Dana S. Peterman, Yale University, dana.peterman@yale.edu

\section{Deciding what's right}

The ACRL Committee on Ethics sponsored "Deciding what's right: Academic library ethics day-to-day," a panel discussion on the ethical challenges faced by academic librarians.

The featured speaker was James Neal (Columbia University). Providing responses were Barbara Jones (Wesleyan University) and Nancy Courtney (Ohio State University).

Neal provided a broad overview of ethics and discussed the relevance of formal ethical codes. Both action and inaction are indicators of ethical behavior, he said. Insofar as "ethics is obedience to the unenforceable," Neal posited that a code must be based upon actual or anticipated situations and give clear advice in order to be useful to those who look to it for guidance.

Barbara Jones responded that a code of ethics is important for the credibility of any professional group and is of special and critical importance to the library profession, in the wake of ever-increasing challenges to the principles of individual privacy and intellectual freedom. Courtney expanded the discussion to consider challenges to individual privacy inherent in the very technology that librarians use to accomplish their daily work.
In the course of the presentation, many key ethical issues facing academic librarians emerged: service for all, censorship of resources, patron privacy, employee rights, and abiding by vendor restrictions on the use of resources. During the discussion portion of the program, audience members had specific questions about RFID, charges for printing and photocopying, digital rights management, and travel support. For those who took Neal's observation that "action is the medium for the expression of ethics" to heart, the program provided plenty of food for thought and action.-Lori Phillips, University of Wyoming Libraries,lphil@uwyo.edu

\section{Digitizing medieval manuscripts}

The ACRL Western European Studies Section and the Slavic and East European Section jointly presented "Digitizing medieval manuscripts: East and West."

David Birnbaum (University of Pittsburgh) opened with a discussion of "Manuscript Description and Quantitative Codicology." He surveyed the development of manuscript description, from the work of the Text Encoding Initiative (TEI) Manuscript Description Task Force to the Repertorium of Old Bulgarian Literature and Letters. Comparing manuscript description as text ("document-centric" XML) and as database ("data-centric" XML), he concluded that prose manuscript description, not requiring philological expertise, is useful for curators digitizing existing manuscript descriptions, supports richer queries, but offers minimal analytical capability, and that structured manuscript description, requiring philological expertise, is useful for philologists who study manuscripts, supports quantitative codicological analysis, and enables queries and analysis across collections.

David Reynolds (Johns Hopkins University) followed with a presentation on the Roman de la Rose Project, a digital collection of six versions of the work from four libraries, designed to enable comparative research. Reynolds discussed early planning of the project, coding and searching options, and controlled vocabulary, and outlined the 
future development of the project, involving plans to add more page images, transcribe the remaining manuscripts, form scholarly workshops and an advisory board, transfer files to a digital repository, transform SGML files into XML, and improve searching capabilities.

Colum Hourihane (Princeton University) outlined the 90-year history of "The Index of Christian Art," founded by eminent art historian and iconographer Charles Rufus Morey in 1917. The collection includes images from early apostolic times to 1400 A.D., with extensions in some areas to the mid-16th century. It is the world's largest electronic database of medieval art, using 28,000 subject terms, and offering flexible searching capabilities. New directions for the index include encompassing Coptic, Armenian, Ethiopian, Syrian, Lebanese, and Jewish art.-Janice T. Pilch, University of Illinois at Urbana-Champaign, pilch@uiuc.edu

\section{Research in diversity}

ACRL's Racial and Ethnic Diversity Committee sponsored a panel of three experts who focused on recruiting culturally diverse LIS faculty and librarians.

Clara Chu (University of California-Los Angeles [UCLA] Graduate School of Education and Information Studies) outlined the Practice, Reflection, Advocacy, Excellence, Inquiry, Solutions (PRAXIS) predoctoral program at UCLA. PRAXIS responds to the shortage of culturally diverse LIS faculty by providing a curriculum on research, policy, technology, and multicultural issues. Students also work with a variety of individual mentors and mentor each other. PRAXIS serves as a best practice model for other LIS programs.

Haipeng Li (Oberlin College) presented the results of a survey of college libraries conducted with Mark Winston that looks at diversity in the areas of collections, services, staffing, and workplace environment. The results show that libraries surveyed make significant efforts to recruit diverse librarians, but that retention is an area that needs more work. Li described two programs in place at his library that address recruitment and retention.
Loriene Roy (School of Information, University of Texas-Austin) discussed the results of a survey of Spectrum Scholars' experiences. Identified strengths include funding to attend a librarian and information science program, providing a network of colleagues, leadership training, and prestige. The need for wider marketing of the program, strengthening the mentoring and leadership training components, and improving communication among the scholars were cited as areas to improve. Roy's statement that "recruitment is every moment," is a call to all librarians to ensure a culturally diverse profession.-Natalie Sommerville, Duke University, natalie. sommerville@duke.edu

\section{Teaching, learning, and leading}

Maryellen Weimer (Berks Lehigh Valley College of Pennsylvania State University) shared ideas from her book Learner-centered teaching: Five key changes to practice with an appreciative audience of more than 500 librarians at the Instruction Section program, "Teaching, learning, and leading: Key roles for librarians in the academic community."

Weimer acknowledged that "learning is a really messy process," then spoke of important changes we can make in the balance of power and responsibility, in the role of the teacher, in the function of content, and in the process of assessment that make the experience more learner-centered. She noted, "You don't create a climate for learning with a statement in the syllabus." She gave concrete and practical examples from her own teaching experience and the literature of ways to engage students in learning, recognizing that this is no small challenge in our current culture.

She admitted that "we [in higher education] have created grade-grubbing monsters, motivated by points, rather than learning." She challenged library educators to make much-needed changes, even in the face of resistance. She offered her own success in witnessing genuine learning as a hopeful model.

In comments about the session, par- 
ticipants commended Weimer's enthusiasm, credibility, humor, and her use of concrete examples and real-life anecdotes. Participants remarked on her ability to lead an interactive session despite the large crowd. Many summed up the session with the word "inspirational."-Diane VanderPo, University of Nevada-Las Vegas, vanderpd@unlv.nevada. edu

\section{Three big ideas transforming scholarly communication}

The SPARC/ACRL Forum drew more than a hundred attendees to hear about significant programs transforming scholarly communication. John Wilbanks, executive director of Science Commons, spoke on "the commons." He explained the Creative Commons movement and the use of the legal mechanisms to facilitate international use of Creative Commons licenses to encourage wide distribution of intellectual property works. These licenses allow the creator to retain copyright and place some restrictions on commercial and derivative use, while permitting users to freely distribute, display, or perform their work.

Debra Lappin (public policy advisor to SPARC and the Alliance for Taxpayer Access) presented "A brief history of the big idea of taxpayer access." She spoke of the campaign for federal policies that would expand access to publicly funded research. Lappin's opening was a quote from Public Library of Science cofounder Harold Varmus: "It is now possible to share the results of medical research with anyone, anywhere, who could benefit from it. How could we not do it?" How, indeed, could the listener fail to be drawn into her crusade? Since the U.S. government spends $\$ 45$ billion to fund scientific and medical research, and the Internet makes it possible to easily share this information, shouldn't this taxpayer-funded research be available freely to every person in the United States?

John Price Wilkin (University of Michigan [UM]) spoke on Googlization and his experience managing the UM library's relationship with Google.-Catherine Wojewodzki, University of Delaware, cathyw@udel.edu $\mathrm{n}$

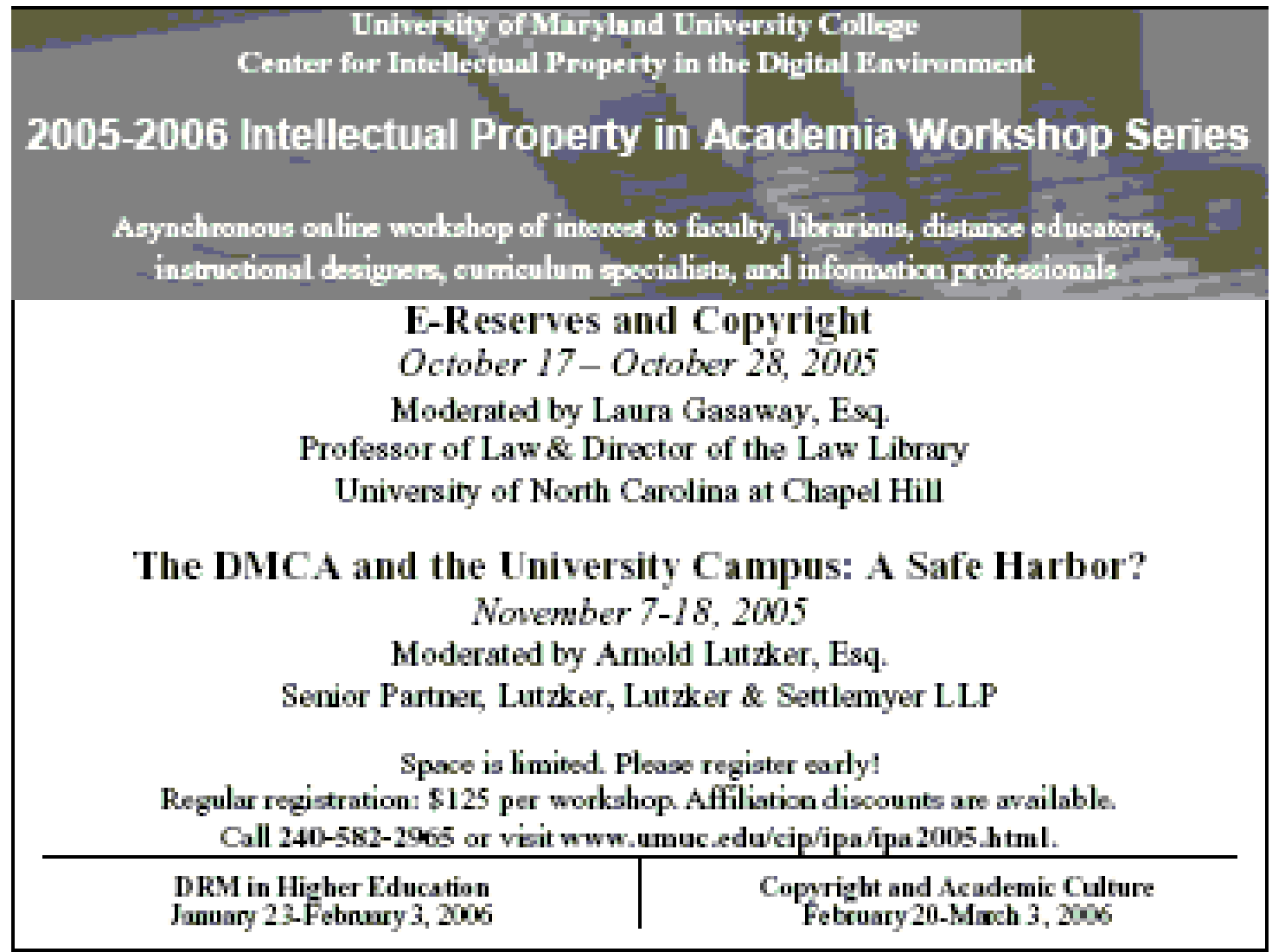

